\title{
ROLE OF COMPUTED TOMOGRAPHY IN EVALUATION OF PATIENTS WITH HISTORY OF CHRONIC HEADACHE
}

\author{
Sanju Rawal ${ }^{1}$, Sadhan Mukhi $^{2}$, Sandip Subedi ${ }^{3}$, Surendra Maharjan
}

\begin{abstract}
INTRODUCTION: Headache is one of the universal experience and one of the most common symptom in medical practice. It is most frequently suffered illness by human beings. As much as 90 percent of individuals have at least one episode of headache each year and severe headache is reported to occur at least annually in 40 percent of the population. Population based estimates suggest that about 4 percent of adults have daily or near daily headache. Since majority of patients who present with chronic or recurrent headache have no significant intracranial abnormalities to be detected on neuroimaging. The main objective of our study was to obtain socio demographic status of patients presenting with history of chronic headache and to assess the role of $\mathrm{CT}$ scan in evaluation of such patients presenting to radiology department from various departments of Universal College of Medical Sciences \& Teaching Hospital (UCMSTH).
\end{abstract}

MATERIAL AND METHODS: All patients with complaints of chronic headache and referred to Department of Radiology from August 2013 to April 2014 were included in the study. Total of 193 cases were included. Intravenous contrast medium was given in all 193 cases. Patients were divided into two groups with normal and abnormal CT findings. Results were tabulated and analyzed for the diagnostic yield from imaging in evaluation of patient with history of chronic headache.

RESULTS: Out of 193 patients, 182 had normal CT (94.31\%) and 11(5.69\%) had abnormal CT findings. Contrast enhanced CT scans did not improve lesion detection. Out of 11 abnormal CT findings 3 of them had intracranial space occupying lesion, 3 had calcified granuloma, 2 of them had sinusitis, 1 had hydrocephalus, 1 cerebral atrophy and 1 with persistent cavum septum pellucidum.

CONCLUSION: The proportion of intracranial abnormalities detected by CT in patients with history of chronic headache in this study was similar to that of previous studies. This corroborates the evidence that the ability of CT scan in detecting intracranial pathology is low in patient with chronic headache with exclusion of any neurological abnormality.

KEYWORDS: Computed Tomography; Chronic headache; Magnetic resonance imaging, Brain imaging

1. Assistant Professor, Department of Radiodiagnosis and Medical Imaging, Universal College of Medical Sciences \& Teaching Hospital Bhairahawa, Nepal

2. Professor and HOD, Department of Radiodiagnosis and Medical Imaging, Universal College of Medical Sciences \& Teaching Hospital Bhairahawa, Nepal

3. Assistant Professor, Department of Neuropsychiatry, Universal College of Medical Sciences \& Teaching Hospital Bhairahawa, Nepal

\author{
For Correspondence \\ Dr. Sanju Rawal \\ Assistant Professor, \\ Department of Radio-diagnosis Medical Imaging \\ Universal College of Medical Sciences, Teaching Hospital, \\ Bhairahawa, Nepal \\ E-mail: sanjurawalchhetri1983@gmail.com
}




\section{INTRODUCTION}

Headache is one of the almost universal experience and one of the most common symptom in medical practice. It is the most frequently suffered illness by human being. As much as 90 percent of individuals have at least one episode of headache each year and severe headache is reported to occur at least annually in 40 percent of the population ${ }^{1}$. Population based estimates suggest that about 4 percent of adults have daily or near daily headache ${ }^{2}$. There are at least two reasons that make the patient consult a physician for headache. One being the patient is afraid of having an intracranial lesion such as brain tumor or aneurysm and the other because the pain is severe enough to negatively influence his or her quality of life.

Headache is a common disorder with many potential causes. The International classification of Headache Disorders (ICHD) is an in depth hierarchical classification of headache published by the international headache society. The first version of the classification, ICHD-1,was published in 1988. The current revision, ICHD-2, was published in $2004^{3}$.

\section{MATERIALS AND METHODS}

This is a Cross Sectional \& Analytical study conducted from August 2013 to April 2014 in Universal College of Medical Sciences Teaching Hospital, Bhairahawa, Nepal. The study was done using a General Electronics (GE) CT E-Plus single slice helical CT scanner. Intravenous iodinated contrast media used for contrast study of the brain in selected patients with an dose equivalent of $1.2 \mathrm{ml} / \mathrm{kg}$ body weight about 100 c.c. The contrast media used in our department was ionic $(300 \mathrm{mg} / \mathrm{ml}$, $350 \mathrm{mg} / \mathrm{ml}$ ) with generic name Iohexol and brand name Lekpamidol. The results were tabulated. The statistical analysis was done by SPSS version 20). The figures and graphs are made from Prism Graph Pad -6 software.

Patients of any age and sex, written informed consent and diagnosed case of chronic headache clinically were included in the study. Whereas patient not giving written consent, having significant head injury, intracranial pathology and positive neurological signs were excluded from study. Ethical clearance was obtained from the institution.

\section{OBSERVATIONAND RESULTS}

Table 1: Age-wise distribution with and without abnormality on imaging

\begin{tabular}{|l|l|l|l|l|l|}
\hline $\begin{array}{l}\text { Abnormal on } \\
\text { CT }\end{array}$ & $<20$ years & $20-40$ years & 40 -60years & $>60$ years & Total \\
\hline Present & $2(4.88 \%)$ & $4(4.40 \%)$ & $3(6.98 \%)$ & $2(11.11 \%)$ & $11(5.70 \%)$ \\
\hline Absent & $39(95.12 \%)$ & $87(95.60 \%)$ & $40(93.02 \%)$ & $16(88.89 \%)$ & $182(94.30 \%)$ \\
\hline Total & 41 & 91 & 43 & 18 & 193 \\
\hline
\end{tabular}

Table 1 represents age-wise distribution with and without abnormality on imaging showed age group $>60$ years showing CT findings abnormalities of about in 2 cases out of total 16 cases with frequency of about (11.11\% )followed by age group 40-60 years showing CT abnormality in 3 cases out of total 40 cases with frequency of about $(6.98 \%)$

Chi-square test is applied to determine the association between abnormal findings in chronic headache patients according to age group. At 5\% level of significance and 3 degree of freedom (d.f), our chi-square value is 1.09659 which is less than tabulated value 2.366 . Thus, we conclude that there is no statistical significance in CT abnormal findings according to age group in chronic headache patients. So the abnormal findings could be found in any age group.

Table 2: Gender distribution with and without abnormality on imaging

\begin{tabular}{|l|l|l|l|}
\hline Abnormality on CT & Males & Females & Total \\
\hline Present & $5(6.10 \%)$ & $6(5.41 \%)$ & $11(5.70 \%)$ \\
\hline Absent & $77(93.90 \%)$ & $105(95.59 \%)$ & $182(94.30 \%)$ \\
\hline Total & 82 & 111 & 193 \\
\hline
\end{tabular}

Table 2 represents Gender distribution with and without abnormality on imaging representing showed equal distribution among male and female with abnormality found in 6 cases out of total 111 cases in females with frequency of about $(5.41 \%)$ and 5 cases out of total 82 cases in males with frequency of about $(6.10 \%)$

Chi-square test is applied to determine the association between abnormal findings in chronic headache patients according to gender. At $5 \%$ level of significance and 1 d.f., chisquare value is 0.03963 which is less than tabulated value 0.455 . In conclusion there is no statistical significance in CT abnormal findings in CT scan of chronic headache patients according to gender. In other words, abnormal findings may occur in any age group randomly.

Table 3: Duration of headache with or without abnormality on imaging

\begin{tabular}{|l|l|l|l|l|}
\hline $\begin{array}{l}\text { Abnormality on } \\
\text { CT }\end{array}$ & $>$ 6months & $12-24$ months & $>24$ months & Total \\
\hline Present & $4(8.16 \%)$ & $5(5.0 \%)$ & $2(4.55 \%)$ & $11(5.70 \%)$ \\
\hline Absent & $45(91.84 \%)$ & $95(95.0 \%)$ & $42(95.45 \%)$ & $182(94.30 \%)$ \\
\hline Total & 49 & 100 & 44 & 193 \\
\hline
\end{tabular}


Table 3 Represents distribution of duration of headache with or without abnormality on imaging showed duration of $<6$ months having total of 4 cases with abnormality out of total 49 cases with frequency of about (8.16\%) followed by duration of 12-24 months with total 5 cases with abnormality out of total 100 cases with frequency of about $(5.0 \%)$ and duration of greater than 24 months having abnormal CT findings in 2 cases out of total 44 cases with frequency of about $(4.55 \%)$ respectively.

Chi-square test is again applied. At 5\% level of significance 2 d.f., chi-square value is 1.00159 which is less than tabulated value 1.386. So we concluded there is no association between abnormal findings in CT scan according to headache duration. In other words abnormal findings may occur at any time period of headache.

\section{Graph 1: Frequency distribution of abnormal CT findings out of total abnormal CT findings}

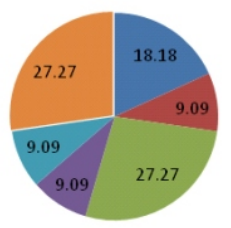

" Sinusitis
- Cavum Septum Pellucidum
= Calcified Granuloma
= Cerbral Atophy
= Hydrocephalous
= Brain Tumour

Represents frequency (\%) distribution of abnormal CT findings out of total abnormal CT findings $(n=11)$ significant number patient having brain tumors and calcified granuloma both comprising total 6 cases with $(n=3)\{27.27 \%\}$ each followed by 2 cases of sinusitis (18.18\%) (Graph 1$)$.

\section{DISCUSSION}

US headache consortium has said that the evidences were insufficient to define the role of neuroimaging in evaluation of chronic headache without neurological abdnormality and recommended larger study involving more than 1000 patients to settle the issue. ${ }^{4}$

Our study had the case with the median age of the patients was 33.78 years. Rate of detection of abnormal CT findings in terms of frequency was detected highest in the age group $>60$ years with abnormality found in 2 cases out of total 18 cases with frequency of about $(11.11 \%)$. One study conducted by Kahn CE et $\mathrm{al}^{5}$, over a period of three years similar to this study found abnormal finding in $10 \%$ and rate of detection of abnormal CT finding were higher in older age group compared to younger. These findings were similar to earlier studies conducted by Carrera GF et $\mathrm{al}^{6}$ and Ayugun D et al ${ }^{7}$ respectively which showed increasing age to be strongly associated with abnormal CT findings in patient with history of chronic headache.
On neuroimaging abnormalities on CT scans were found higher in patient with duration of chronic headache $>6$ months - $<12$ months comprising shorter duration compared to other two group with total 4 cases $(8.16 \%)$ out of total 45 cases. The above findings were somewhat similar to the study conducted by Evans RW et al, who concluded rate of finding abnormality in patient with chronic headache in CT scan is higher in patients with shorter duration compared to the longer duration chronic headache not associated with neurological abnormality.

Our study showed abnormal CT findings were present in total 6 female cases and 5 male cases .No significant difference according to gender distribution could be concluded from our study. There are no available sources in literature in order to determine the relationship of gender based distribution and abnormal CT findings in patient with history of chronic headache.

In relation to frequency distribution in patients having abnormal CT findings our study showed out of all the abnormal cases. Only 3 cases out of total 193 cases showed ICSOL rest did not have significant finding that could alter patient management. This observation was similar to the study conducted by Sherf $M$ et $\mathrm{al}^{9}$. Similarly in one of the study conducted by Evans $\mathrm{R}$ et $\mathrm{al}^{8}$, the ICSOL was found in only $0.8 \%$ of the case hence similar to the study of ours.

Various studies have been performed in order to evaluate the role of neuroimaging in detecting abnormalities in patients with chronic headache without neurological abnormality similar to our studies and findings were similar. Study conducted in 1995 by Maytal J et $\mathrm{al}^{10}$, also had similar purpose as ours in determining the value of neuroimaging in children with chronic headache and concluded that neuroimaging have a very limited role in evaluating chronic headache

According to a meta analysis ${ }^{4}$, abnormalities detected in CT scans in patients with unspecified headache ranged from $0.0 \%$ to $6.7 \%$ in ten studies, and our study falls in that range with abnormal CT Findings in $5.9 \%$ of the total cases studies.

In our present study out of 193 cases, contrast enhanced CT scan was performed in all of 193 cases $(100 \%)$ as directed by the advising practitioners in U.C.M.S-T.H. Contrast was given to all the patient presenting with history of chronic headache without neurological abnormality with normal appearing unenhanced CT scans in order to not to miss any lesion. As concluded in one of the study by Dumas MD et $\mathrm{al}^{11}$, about $17.4 \%$ of the scans may have missed lesion for not performing contrast enhanced CT scan.

One study in Japan done by Tsushima et $\mathrm{al}^{12}$, concluded MR is unrewarding technique in the evaluation of patients with chronic or recurrent headache. Only two $(0.7 \%)$ of the cases 
having significant abnormalities concluding MR imaging is unrewarding as considered. Similarly Wober-Bingol ${ }^{13}$ conducted a study in 2006 , vast majority $82.3 \%$ had normal imaging findings and structural changes that had minimal or no pathological relevance and a causal relationship to patient's headache were found in $17.7 \%$ concluding MRI is not required for routine examination in case of chronic or recurrent headache.

One study was performed by Dumas MD et $\mathrm{al}^{11}$ to find out the cost of finding intracranial pathology such as brain tumor. It concluded with cost of almost 18 thousand dollars in order to find out any significant pathology comparing with the above study, as only $5.69 \%$ of our cases had abnormal CT findings out of 193 cases making high cost effectiveness ratio.

\section{CONCLUSION}

In the patients with chronic headache with exclusion of neurological abnormality, CT detected abnormalities is 5.69 $\%$. There is no association between abnormal findings in CT scan of chronic headache patients according to age, gender and duration. Highest probability for detection of abnormalities was found in older age group i.e. greater than 60 years. The yield from imaging in patients with only chronic headache and exclusion criteria of neurological abnormality was low. Screening in headache with CT not only helps in identifying an abnormality but also helps to rule out structural cause for chronic headache thereby reducing patient apprehension in today's setting. .The result is consistent with findings of previous studies. This further strengthens the fact that the ability of CT scan in detecting abnormalities in patient with history of chronic headache is very low .CT brain is a useful screening modality in evaluating patients with headache either to identify or to rule out structural abnormality. However larger studies with large number of sample size and longer duration of studies may be needed to establish the role of CT scan brain in evaluation of patient with history of chronic headache.

\section{REFERENCES}

1. Fauci As, Braunwald E, Kasper, Hauser SL, Longo DL, Jameson JL et al.Headache. In: Harrisons principles of Internal Medicine.17th ed. New York: Mc Graw Hill; 2008. P. 95-106(Vol. 1)

2. Goads by PJ, Ranskin NH. et al. Headache. In: Harrison's principle of Internal Medicine. 17th Ed. New York: Mc Graw Hill; 2008.p. 103(Vol. 1)

3. Headache classification Committee of the International Headache Society. Classification and diagnostic criteria for headache disorders, cranial neuralgia and facial pain. Second Edition. Cephalalgia 2004, 24(Suppl 1): 1-160
4. Frishberg BM, Rosenber JH, Matchar DB. Evidence based guideline in the primary care sitting : neuroimaging in patients with non acute headache.U.S. Headache consortium. Web site. Available at: www.aan.com

5. Kahn CE Jr, Sanders GD, Lyons EA, Kostelic JK, Mac Ewan $D W$, Gordon WL. Computed tomography for nontraumatic headache: Current utilization and cost-effectiveness

6. Carrera GF, Gerson DE, Schnur J, Mc Neil BJ. Computed Tomography of the brain in patients with headache or Temporal lobe epilepsy: Finding Cost effectiveness. J Comput Assist Tomogr.1977;1(2):200-203 http://dx.doi.org/10.1097/00004728-197704000-00008 PMid:97333

7. Ayugun D, Bildik F. Clinical warning criteria in Evaluation by computed Tomography the secondary Neurological Headaches in Adults. Eur JNeurol 2003; 10:437-42

http://dx.doi.org/10.1046/j.1468-1331.2003.00645.x

8. Evans RW. Diagnostic Testing for the Evaluation of Headaches Neurological Clinic 2009; 27:393-415

http://dx.doi.org/10.1016/j.ncl.2008.11.009 PMid:19289222

9. Sherf M. Evaluate the indications and results of referral for brain computerized tomography (CT) by primary care physicians. Euro J Neurol. 2003; 33:182-96

10. Maytal J, Bienkowski RS, Patel M, Eviatar L. The value of brain imaging in children with headaches. Pediatrics 1995; 96:41316 PMid:7651770

11. Dumas MD, Pexman JH, Kreeft JH, Computed tomography evaluation of patients with chronic headache. CMAJ. 1994 Nov 15; 151(10):1447-52 PMid:7954139 PMCid:PMC1337409

12. Tsushima $Y$, Endo $K$ et al. MR imaging in the evaluation of chronic or recurrent headache. Radiology 2005; 235:575-579 http://dx.doi.org/10.1148/radiol.2352032121 PMid:15858096

13. Wober-Bingol C, Wober C, Prayer D, Wagner-Ennsgraber C, Karwautz A, Vesely C, Zebenholzer K, Feucht M. Magnetic resonance imaging for recurrent headache in childhood and adolescence. Headache 1996; 36:83-90 http://dx.doi.org/10.1046/j.1526-4610.1996.3602083.x PMid:8742679 